\title{
Changing incidence of infantile hypertrophic pyloric stenosis
}

\author{
E G KNOX, E ARMSTRONG, AND R HAYNES \\ Health Services Research Centre, University of Birmingham and West Midlands Regional Health Authority, \\ Birmingham
}

SUMMARY The incidence of infantile hypertrophic pyloric stenosis was measured in the West Midlands Health Region between 1974 and 1980. It increased from $2 \cdot 1 / 1000$ Caucasian births in 1974 to $3 \cdot 5 / 1000$ in 1980 and reflects a reported increase in Central Scotland. Several artefacts were excluded-for example, repeat admissions to the same hospital, transfers to other hospitals, and changes in treatment and in diagnostic standards. Two main demographic changes were excluded as explanations, ethnic changes and changes in the birth rank distribution. The increase is therefore considered real and may be related to changes in breast feeding practice.

An unprecedented rise in the incidence of infantile hypertrophic pyloric stenosis (IHPS) was reported in Scotland in 1978 and 1979..$^{1}$ The incidence rose from $2 \cdot 2 / 1000$ births in $1970-7$ to $5 \cdot 2 / 1000$ births in 1978 to $8 \cdot 8 / 1000$ births in 1979 . The numbers seem to exclude a random effect and the question therefore arises whether a similar increase occurred in other places at the same time; and if it did, how it may be explained.

Certain non-biological explanations have to be excluded. The first is the question of a changing level of ascertainment-that is, past underdiagnosis or present overdiagnosis. The second possibility is demographic change: an alteration in distribution of birth rank in the population. IHPS is more frequent in earlier than later births and a 'shortening' of the birth rank distribution would cause an increase in crude incidence. Finally, the effects of a changing ethnic distribution have to be considered. A high incidence of IHPS in immigrants would produce an artefactual increase; a low incidence may mask, or partially mask, a true increase. Only when these potential artefacts have been excluded can it be supposed that a true biological change has occurred. The purpose of this study was to examine these questions in the West Midlands Health Region.

\section{Materials and methods}

Numbers of deaths from IHPS and discharge from hospital of patients with IHPS were extracted from the West Midlands Health Region hospital activity analysis (HAA) files for the period 1974-80.
These data cover the whole of the West Midlands Health Region except the Wolverhampton hospitals. (Wolverhampton Area Health Authority had not conformed with the statistical format prescribed in the regional HAA scheme and analyses of this kind are impossible for Wolverhampton.) To eliminate double counting through repeat admissions and transfers between hospitals all cases of IHPS were sorted in order of date of birth and then identified by both name and date of birth on a computer listing. With this technique repeat admissions of the same child were printed adjacent to each other. Data were supplied on the month and year of death or discharge home, the sex of the child, health district, and treatment. Numbers of live births for the West Midlands Health Region, excluding Wolverhampton, were obtained from Office of Population Censuses and Surveys (OPCS) reports. These denominators are approximate in that not all patients admitted to Wolverhampton hospitals are Wolverhampton residents and not all Wolverhampton residents go to Wolverhampton hospitals. The degree of cross boundary transfer is, however, small and no obvious changes occurred over the investigation period.

Birth rank distributions of legitimate live births in the West Midlands were also obtained from OPCS reports for the period 1974-80. The proportional distribution for the full region was accepted without further modification as appropriate to the Wolverhampton excluded data, and the birth rank distribution for legitimate births was treated as a sufficiently accurate approximation for all births. Birth rank was not recorded on the HAA records. 
Ethnic origin is not recorded on HAA records but a high proportion of births to Indian and Pakistani families may be identified by surname and these 2 groups constitute by far the largest ethnic minority in this region. These births were identified for the IHPS cases themselves. OPCS reports provided data on live births for parts of the region (see below) with separate identification according to the mother's country of birth. This is not the same thing as 'ethnic group.' The nearest available approximation, which we used, was births to foreign born (excluding Irish) women.

Statistical analyses were based upon annual rates per 1000 live births. Indirect standardisation procedures were used to correct for birth rank changes. Indirect methods were necessary because of the absence of birth rank specifications in the HAA records. The birth rank specific 'reference incidences' used for this standardisation process were the estimates obtained in Birmingham in an earlier period, 1940-9. ${ }^{2}$ Although this material is now rather old, it has the advantage from our point of view of local origins. The birth rank differences reported in this study were also steeper than in many other investigations. As long as the reference material is used to provide for relative standardisation across the period of current interest and not for absolute standardisation, the remoteness of the period to which the material refers is no great disadvantage. The steepness of the birth rank differential provides us with a birth rank standardisation that is conservative. Thus any errors are likely to be in overcompensation, minimising rather than exaggerating any true trend.

\section{Results}

Table 1 gives the numbers of cases, the numbers of live births, and the incidence per 1000 live births for the years 1974-80 in the West Midlands Health Region (excluding Wolverhampton). Kerr's estimates $^{1}$ for Central Scotland are attached for comparison. An 'adjusted' West Midlands incidence, calculated to correspond with results for a Caucasian population, is also included.

The West Midlands data did not show the same dramatic changes as the Scottish data, but the rise in incidence was fairly steady over the period. The results may also be compared with an incidence estimate of $3.0 / 1000$ live births in the city of

Table 1 Incidence of infantile hypertrophic pyloric stenosis per 1000 live births in the West Midlands Region (excluding Wolverhampton) between 1974 and 1980

\begin{tabular}{|c|c|c|c|c|c|c|c|}
\hline & 1974 & 1975 & 1976 & 1977 & 1978 & 1979 & 1980 \\
\hline $\begin{array}{l}\text { No of cases } \\
\text { Live births } \\
\text { Overall incidence } \\
\text { Adjusted incidence* } \\
\text { Incidence in Central } \\
\quad \text { Scotland }\end{array}$ & $\begin{array}{l}125 \\
66378 \\
1 \cdot 88 \\
2 \cdot 13 \\
2 \cdot 2\end{array}$ & $\begin{array}{l}138 \\
61941 \\
2 \cdot 23 \\
2 \cdot 52 \\
2 \cdot 2\end{array}$ & $\begin{array}{l}162 \\
59329 \\
2 \cdot 73 \\
3 \cdot 09 \\
1 \cdot 5\end{array}$ & $\begin{array}{l}149 \\
57619 \\
2 \cdot 59 \\
2 \cdot 92 \\
2 \cdot 2\end{array}$ & $\begin{array}{l}184 \\
60496 \\
3 \cdot 04 \\
3 \cdot 44 \\
5 \cdot 2\end{array}$ & $\begin{array}{l}208 \\
63637 \\
3 \cdot 22 \\
3 \cdot 64 \\
8 \cdot 8\end{array}$ & $\begin{array}{l}210 \\
67466 \\
3 \cdot 11 \\
3 \cdot 52 \\
-\end{array}$ \\
\hline
\end{tabular}

* As for Caucasian births.

Table 2 Overall incidence of infantile hypertrophic pyloric stenosis according to sex, method of treatment, and health district

\begin{tabular}{|c|c|c|c|c|c|c|c|}
\hline & 1974 & 1975 & 1976 & 1977 & 1978 & 1979 & 1980 \\
\hline $\begin{array}{l}\text { Sex } \\
\text { Boy } \\
\text { Girl } \\
\text { Boys:girls }\end{array}$ & $\begin{array}{l}2 \cdot 85 \\
0 \cdot 87 \\
3 \cdot 3\end{array}$ & $\begin{array}{l}3 \cdot 47 \\
0 \cdot 90 \\
3 \cdot 9\end{array}$ & $\begin{array}{l}4 \cdot 06 \\
1 \cdot 32 \\
3 \cdot 1\end{array}$ & $\begin{array}{l}3 \cdot 89 \\
1 \cdot 19 \\
3 \cdot 3\end{array}$ & $\begin{array}{l}4 \cdot 83 \\
1 \cdot 13 \\
4 \cdot 3\end{array}$ & $\begin{array}{l}5 \cdot 01 \\
1 \cdot 33 \\
3 \cdot 8\end{array}$ & $\begin{array}{l}5 \cdot 01 \\
1 \cdot 15 \\
4 \cdot 4\end{array}$ \\
\hline $\begin{array}{l}\text { Treatment } \\
\text { Surgery } \\
\text { Other } \\
\text { Surgery:other }\end{array}$ & $\begin{array}{l}1 \cdot 46 \\
0.42 \\
3 \cdot 5\end{array}$ & $\begin{array}{l}1 \cdot 79 \\
0 \cdot 44 \\
4 \cdot 1\end{array}$ & $\begin{array}{l}2 \cdot 17 \\
0 \cdot 56 \\
3 \cdot 9\end{array}$ & $\begin{array}{l}2 \cdot 17 \\
0 \cdot 42 \\
5 \cdot 2\end{array}$ & $\begin{array}{l}2 \cdot 46 \\
0 \cdot 58 \\
4 \cdot 2\end{array}$ & $\begin{array}{l}2 \cdot 72 \\
0 \cdot 50 \\
5 \cdot 4\end{array}$ & $\begin{array}{l}2 \cdot 64 \\
0.47 \\
5 \cdot 6\end{array}$ \\
\hline $\begin{array}{l}\text { Health district } \\
\text { Inside West Midlands conurbation* } \\
\text { Outside West Midlands conurbation } \\
\text { Inside:outside incidence ratio }\end{array}$ & $\begin{array}{l}2 \cdot 03 \\
1 \cdot 72 \\
1 \cdot 2\end{array}$ & $\begin{array}{l}2 \cdot 44 \\
2 \cdot 01 \\
1 \cdot 2\end{array}$ & $\begin{array}{l}2 \cdot 85 \\
2 \cdot 61 \\
1 \cdot 1\end{array}$ & $\begin{array}{l}2 \cdot 48 \\
2 \cdot 70 \\
1 \cdot 0\end{array}$ & $\begin{array}{l}2 \cdot 85 \\
3 \cdot 24 \\
0 \cdot 9\end{array}$ & $\begin{array}{l}3 \cdot 52 \\
2 \cdot 91 \\
1 \cdot 2\end{array}$ & $\begin{array}{l}3 \cdot 48 \\
2 \cdot 73 \\
1 \cdot 3\end{array}$ \\
\hline $\begin{array}{l}\text { Health district: boys only } \\
\text { Inside West Midlands conurbation } \\
\text { Outside West Midlands conurbation } \\
\text { Inside:outside incidence ratio }\end{array}$ & $\begin{array}{l}2 \cdot 99 \\
2 \cdot 70 \\
1 \cdot 1\end{array}$ & $\begin{array}{l}3 \cdot 88 \\
3 \cdot 05 \\
1 \cdot 3\end{array}$ & $\begin{array}{l}4 \cdot 19 \\
3 \cdot 92 \\
1 \cdot 1\end{array}$ & $\begin{array}{l}4 \cdot 09 \\
3 \cdot 69 \\
1 \cdot 1\end{array}$ & $\begin{array}{l}4 \cdot 35 \\
5 \cdot 33 \\
0 \cdot 8\end{array}$ & $\begin{array}{l}5 \cdot 44 \\
4 \cdot 57 \\
1 \cdot 2\end{array}$ & $\begin{array}{l}5 \cdot 67 \\
4 \cdot 32 \\
1 \cdot 3\end{array}$ \\
\hline
\end{tabular}

*The West Midlands conurbation (Wolverhampton excluded) consists of Birmingham, Coventry, Dudley, Sandwell, Solihull, and Walsall. 
Birmingham for the period 1940-9, based upon accurately ascertained data. ${ }^{2}$ (The population was then almost entirely Caucasian.) The variation between years is greater than can be attributed to chance $(\mathrm{P}<0 \cdot 001)$.

Ascertainment artefact. Evidence of ascertainment artefact was sought through examination of the data for evidence of heterogeneities. The results of some of these examinations are given in Table 2. They relate mainly to the child's sex, the method of treatment, and the health district. Three major sources of diagnostic or ascertainment artefact can be excluded; these are:

\section{(1) Overdiagnosis of IHPS}

Overdiagnosis of IHPS in vomiting babies results in a less extreme sex ratio, because vomiting without IHPS occurs in infants of both sexes with approximately equal frequency. A rise in apparent incidence through an artefact of this kind should have resulted in a lessening of the sex ratio. In fact, the sex ratio was more extreme in the last 3 years than in the first 4.

\section{(2) Treatment without surgery}

A second cause of overdiagnosis is treatment without surgery. An artefactual increase here would be accompanied by an increase in the ratio of medically to surgically treated cases. In fact, the incidence increased in parallel among medically and surgically treated cases, with a slight increase in surgically treated cases.

\section{(3) Underinvested paediatric services}

Underdiagnosis in the early years may have been associated with underinvested and underdeveloped paediatric services. In this case the apparent increase would occur in the more peripheral health districts, with their relative lack of finance and development. There was indeed a slight overall difference between the metropolitan and peripheral districts but it did not change appreciably over the period and the temporal increase was visible in both. There is therefore no evidence that an artefact of this kind could have explained the increase.
Demographic changes. The effects of the 2 main recent demographic changes, ethnic changes and changes in the birth rank distribution, were then examined. The major changes in the ethnic distributions of West Midland births occurred before the period with which we were concerned but there was a slow increase in the proportion of immigrant births. Exact figures are not available, partly because ethnic group is not recorded on HAA data and partly because the OPCS tabulations of births against mother's country of birth are incomplete and refer only to selected districts. Within the West Midlands Metropolitan County the proportion of foreign born mothers (excluding Irish mothers and excluding Wolverhampton) rose from $17.1 \%$ in 1974 to $22.0 \%$ in 1980 . In Warwickshire and Staffordshire, for which data are available for 1978-80, the proportion of births to foreign mothers was only $5.4 \%$. If we assume that the births in the nonmetropolitan areas followed this lesser value, then the overall figure for the whole region over the 7 years must have been about $13.9 \%$, rising from about $10.7 \%$ to about $14.6 \%$. Only $31(2.6 \%)$ cases of IHPS have names to suggest such origins, which indicates that the incidence is rather low in these ethnic groups and that the incidence in the infants of British born mothers is somewhat higher than the overall West Midlands incidence. We calculate the necessary factor for the latter at 1.13 , and this is the basis of the 'adjusted' incidences given in Table 1. Ethnic changes are more likely therefore to have masked partially the extent of the general increase in the period 1974-80 than to have been responsible for it.

A 'shortening' of the birth rank distribution could produce a rise in crude incidence because the disease is more frequent in infants of early birth rank. Birth ranks were not recorded for the IHPS cases but only for the total live births, so an indirect method of standardisation was necessary. McKeown, McMahon, and Record ${ }^{2}$ measured the incidence in infants of 1st, 2nd, 3rd, and 4th or later rank (in Birmingham in the years 1940-9), and found values of $4 \cdot 3,2 \cdot 8,2 \cdot 5$, and $1 \cdot 4$. These rank specific rates were applied to the population birth rank distributions to calculate the numbers of cases that

Table 3 Birth rank standardised incidence ratio for infantile hypertrophic pyloric stenosis

\begin{tabular}{|c|c|c|c|c|c|c|c|}
\hline & 1974 & 1975 & 1976 & 1977 & 1978 & 1979 & 1980 \\
\hline Observed cases & 125 & 138 & 162 & 149 & 184 & 208 & 210 \\
\hline Expected cases & $195 \cdot 6$ & $182 \cdot 3$ & $173 \cdot 7$ & $169 \cdot 1$ & $177 \cdot 1$ & $187 \cdot 0$ & $193 \cdot 0$ \\
\hline Ratio $(\times 113)^{*}$ & $72 \cdot 2$ & $85 \cdot 5$ & $105 \cdot 4$ & 99.6 & $117 \cdot 4$ & $125 \cdot 7$ & $122 \cdot 9$ \\
\hline \multicolumn{8}{|l|}{ Confidence limits } \\
\hline Upper & $86 \cdot 1$ & $101 \cdot 1$ & $123 \cdot 0$ & $117 \cdot 0$ & $135 \cdot 6$ & $144 \cdot 0$ & $140 \cdot 8$ \\
\hline Lower & $60 \cdot 6$ & $72 \cdot 4$ & $90 \cdot 3$ & $84 \cdot 7$ & $101 \cdot 5$ & $109 \cdot 6$ & $107 \cdot 4$ \\
\hline
\end{tabular}

*See text-Demographic changes. 
would have occurred if the 1940-9 rates had obtained. Table 3 sets out these expected values alongside the observed values and calculates the ratio between them $(x 100)$ in a manner analogous with a standardised mortality ratio. Finally, these values were multiplied by the ethnic change factor $(1 \cdot 13)$, and the $95 \%$ confidence limits were also calculated.

The temporal increase in incidence evidently resists birth rank standardisation, and cannot therefore be explained in terms of this particular demographic change. The standardised incidence in 1974 was appreciably less than in Birmingham in 1940-9, and the standardised incidence in 1978-80 was appreciably greater.

\section{Discussion}

The West Midlands data did not exhibit the same dramatic changes shown in Central Scotland, but there was a substantial and seemingly genuine increase in incidence - that is, there is no evidence of an artefact of changing diagnostic practice, of hospital admission or registration practice, of treatment patterns, or of data reporting procedures. Nor may the changes be explained in terms of demographic changes relating either to ethnic group or to birth rank.

HAA data in general contain inaccuracies. ${ }^{34}$ Coding is usually performed by clerks rather than by doctors, there is no routine system of double blind coding, or of quality control through reference back to original records. Statistical returns refer to hospital discharges rather than to individual patients and the main purposes of HAA registers are not those of epidemiological analysis. HAA in the West Midlands was established, however, in its present form as far back as 1969, and there have been no substantial changes in coding or data handling practice during the period of this study, and no changes in regional boundaries. We were unable to find any procedural changes between 1974 and 1980 that could explain an increase in incidence of approximately $60 \%$. Compared with other diagnostic codings, IHPS is unambiguous and in surgically treated cases is backed by a coding of Ramstedt's procedure, which is used for no other disease.

This report and the Central Scotland report are not the only investigations to record short term changes in incidence. MacMahon, Record, and McKeown ${ }^{5}$ noted a general increase in Birmingham between 1940 and 1949. The incidence was at its lowest in 1941 at $2 \cdot 1 / 1000$, and in 1949 it was $4 \cdot 2 / 1000$. McLean ${ }^{6}$ studied IHPS in the Aberdeen region in successive 4 year periods beginning in 1938, to 1953; the incidence rose from 2.4 to 2.7 to
$3 \cdot 6$ to $4 \cdot 5 / 1000$. In retrospect, systematic changes in the incidence of IHPS seem to be one of its enduring characteristics. It is possible that periods of increase attract the attentions of investigators more readily than do periods of decrease and it is these that are reported.

What causes these changes? Dodge, working in Belfast, ${ }^{7}$ found that $22 \%$ of cases of IHPS were still being breast fed at 1 week of age compared with $15.9 \%$ of controls. Differences in feeding patterns were also noted by Gerrard, Waterhouse, and Maurice, ${ }^{8}$ although they were interested more in frequency of feeding than in type of feeding and in age of onset rather than in the fact of occurrence per se. Dodge suggested that 'some factor' transmitted in the milk might contribute to the aetiology of the disease. It is therefore of interest that the incidence of breast feeding changed during the period of the study reported here. A survey carried out in England and Wales ${ }^{9}$ showed that $51 \%$ of infants were breast fed in 1975 and $67 \%$ in 1980. In the West Midlands Health Region the proportion increased from $48 \%$ in 1975 to $63 \%$ in 1980 , a proportional increase of $31 \%$ on the earlier figure. The definition of breast feeding used in that survey may not be directly relevant to the etiology of IHPS, so it is not possible to relate proportional changes of disease incidence and of breast feeding in any quantitative way. We note only the qualitative parallel.

\section{References}

1 Kerr AM. Unprecedented rise in incidence of infantile hypertrophic pyloric stenosis. Br Med J 1980; 281 : 714-5.

2 McKeown T, MacMahon B, Record RG. The incidence of congenital pyloric stenosis related to birth rank and maternal age. Annals of Eugenics 1951 ; 16: 249-59.

3 Rees JL. Accuracy of hospital activity analysis data in estimating the incidence of proximal femoral fracture. Br Med J 1982; 284: 1856-7.

4 Whates PD, Birzgalis AR, Irving M. Accuracy of hospital activity analysis operation codes. $\mathrm{Br} M e d \mathrm{~J} 1982$; 284: $1857-8$.

5 MacMahon B, Record RG, Mckeown T. Congenital pyloric stenosis: an investigation of 578 cases. $\mathrm{Br} \mathrm{J} \mathrm{Soc}$ Med 1951; 5: 185-92.

- McLean MM. The incidence of infantile pyloric stenosis in the north east of Scotland. Arch Dis Child 1956; 31 : 481-2.

7 Dodge JA. Infantile hypertrophic pyloric stenosis in Belfast, 1957-1969. Arch Dis Child 1975; 50: 171-8.

8 Gerrard JW, Waterhouse JAH, Maurice DG. Infantile pyloric stenosis. Arch Dis Child 1955; 30: 493-6.

9 Martin J, Monk J. Infant feeding in 1980. (OPCS, Social Survey Division). London: HMSO, 1982.

Correspondence to Professor E G Knox, Health Services Research Centre, University of Birmingham, Edgbaston, Birmingham B15 2TJ.

Received 21 April 1983 